\title{
PITFALLS AND PARADOXES: COPING WITH THE CAPABILITIES-RIGIDITIES DILEMMA IN WHOLE NETWORKS ${ }^{1}$
}

\author{
William R. Carter \\ University of North Texas • Denton, Texas \\ Phillip E. Davis \\ University of North Texas • Denton, Texas \\ Julia L. Herchen \\ University of North Texas • Denton, Texas \\ Vallari Chandna \\ University of North Texas • Denton, Texas
}

\section{ABSTRACT}

Emergent interorganizational forms intent on long-term competitive performance at the network level are affecting markets and gaining scholarly attention. Whole networks are an example of such organizations. Managerial paradoxes result from these informal, non-hierarchical structures when they seek long-term competitive advantage. Applying paradox theory and research on ambidexterity, we conclude that, counter intuitively, formalized governance is necessary to sustain informal competitive entity success. Contrary to traditional network theory, social capital mechanisms and trust are not solely adequate. We examine challenges facing whole networks and propose three governance strategies to address them: (1) formalized governance with adequate authority; (2) centralized leadership with decentralized decision-making; and (3) provisions for managing membership composition. We discuss implications for practitioners and scholars and suggest research paths for validating and extending this theory.

\section{INTRODUCTION}

Interfirm networks are altering the competitive landscape (Parkhe, Wasserman, \& Ralston, 2006). The benefits of networks for rapid technical innovation, for example, have led to widespread government involvement in creating science parks and incubators to foster economic development and growth of small, entrepreneurial firms (Phan, Siegel, \& Wright, 2005). Networks can offer access to resources, 
capabilities, and markets not easily available to individual firms. Networks can thus achieve valuable competitive advantage for themselves and their members (Meiseberg \& Ehrmann, 2012). Though interfirm organizations have been a topic of study for several decades, there is a "growing set of pioneering organizational experiments" intent on leveraging the advantages of networked business models (Miles, Miles, Snow, Blomqvist, \& Rocha, 2009; p 61). Advances in information and communication technology have allowed unique organizational forms such as virtual organizations to emerge for both short-term and going-concern motivations (Pedersen \& Nagengast, 2008; Riemer \& Klein, 2008). Non-traditional network forms are becoming pervasive and increased competitive intensity is fueling further network form innovation (Parkhe et al., 2006). It is thus not surprising that scholars are increasingly studying emergent organizational forms such as virtual organizations the V-form - (Riemer \& Klein, 2008), innovation networks - the I-form (Miles et al., 2009), and whole networks (Provan, Fish, \& Sydow, 2007).

The modern economy and much of the competition within it is knowledge-based. Customization, flexibility, and the rapid creation, sharing, and value conversion of knowledge are often key success factors for firm success (Contractor \& Lorange, 2002; Miles et al., 2009. These competitive demands are resulting in the continued rise of networked organizations. As a secondary result, the increase in interfirm networks is leading to competition between networks and between networks and individual firms (Gimeno, 2004; Guidice, Vasudevan, \& Duysters, 2003). As these emergent network forms flex their competitive muscle, many individual firms, especially small and medium sized firms (Meiseberg \& Ehrmann, 2012), are likely to feel pressure to create or join rival networks in order to survive and compete with these new organizations. Thus, the emergence of such competitive networks is likely to influence the creation of more and more such organizations. Firms in affected markets that are not members of a network may find themselves with strategic disadvantages that are individually insurmountable. Thus, an increasing number of managers may find themselves forming, joining, or considering joining such networks in order to access the unique advantages (or necessary survival benefits) they may afford.

Various descriptors distinguish types of networks that involve specific strategic intent. The literature has addressed dynamic networks (Snow, Miles, \& Coleman, 1992), strategic networks (Jarillo, 1993; Sydow \& Windelar, 1998) and the 'network für such' (network for itself) (Raab \& Kenis, 2009) to distinguish networks with a unifying, common purpose from those designed for knowledge sharing, R\&D co-development, supply-chain efficiencies, or collaborative equity investment in new 
ventures. Recently, researchers have conceptualized whole networks as those interorganizational networks involving a unified goal-orientation, substantial individual member autonomy, and a nonhierarchical structure (Kilduff \& Tsai, 2003; Provan et al., 2007). To help frame our analysis of these emergent forms, we ground this paper in the work of Provan and colleagues to use whole networks as an example of an emergent interfirm organization possessing unique operational and competitive characteristics.

Network failure is usually attributable to weaknesses in network management (Miles \& Snow, 1992) such as unclear procedures, poorly coordinated resource allocations, and imbalances of power and influence (Meiseberg \& Ehrmann, 2012). Much research has been conducted on governance within traditional network theory (Jones, Hesterly \& Borgatti, 1997). However, we find a deficient amount of research probing the challenges of management and governance systems in emergent forms such as whole networks. Our point of departure from prior research is to focus on how the unique characteristics of whole networks bring about paradoxical challenges and fundamental agency problems. Though whole networks organize to leverage the benefits of flexibility and informality, we argue that sustaining such an organization over time requires both informality in structure and formality in governance. As one anonymous reviewer commented, there is irony in the prospect that an organizational form of independent firms, dedicated to flexibility, informality, and non-hierarchical relationships may require some formality of centralized governance in order to sustain performance. Indeed, this is the essential paradox of these emerging network forms.

We argue that, left unattended, adaptation of the network and its independent members over time produces a high probability of fractures to the intuitively desirable mechanisms of trust and reciprocity. Network theory informs that trust is a primary mechanism for managing transaction costs and opportunism (Goerzen, 2007). Over time, however, trust can become increasingly fragile (Granovetter, 1985). Ironically, the development and management of such informal social capital assets requires management process and structure in these loosely formed, emergent organizations (Reimer \& Klein, 2008). Further, Meiseberg and Ehrmann (2012) note that without proper governance, relational network communications may become biased, sub-group and individual member power positions and resource dependency effects may emerge, and untimely and inefficient resource coordination may inhibit the sustainability of competitive advantage. There are numerous paradoxes inherent in network theory (Parkhe et al., 2006). Addressing all of such challenges in whole network type organizations is beyond the limitations of one paper. Therefore, we fo- 
cus attention on one core issue: the capabilities-rigidities dilemma (Leonard-Barton, 1992).

To sustain performance, organizations must not only exploit and defend their current advantages, but they must also explore for new advantages and avoid inertial forces that can inhibit adaptation when conditions reduce or destroy the value of their current strengths. Applying prior theory related to balancing exploitation and exploration and the achievement of ambidexterity in firms (O'Reilly \& Tushman, 2008; Raisch \& Birkinshaw, 2008), we posit that whole networks have access to several of the same coping strategies empirically supported for helping firms face the capabilities-rigidities dilemma. However, due to unique characteristics of whole networks, we emphasize that they face distinctive challenges that require governance mechanisms not relevant to the management of other organizational forms. Such unique governance and management challenges involved in emerging network organizations have been generally overlooked by researchers (Riemer \& Klein, 2008), and thus are important topics to be addressed.

The propositions set forth in this paper not only offer a unique, network-level view of competitive intent and the implications of developing and exploiting capabilities, they also contribute to expanding network-level applications of firm-level performance theories. It is our hope that this analysis will aid managers who are founders or members of these emergent network forms as well as those who may at some point consider involvement in such a network. Further, this work aims to provide value to researchers by helping to clarify and distinguish whole networks from other organizational forms and to spur curiosity toward the investigation of the unique paradoxical governance mechanism we posit as necessary for the long-term performance of these emergent organizations.

\section{A REVIEW OF THEORETICAL BACKGROUND}

\section{Emergent Network Organizations}

Riemer and Klein (2008) characterize virtual organizations (what they term the V-Form) as those networks of firms connected through communication technology that allows them to span spatial and temporal boundaries. These organizations are composed of independent firms acting as a single entity toward customers and competitors (Kasper-Fuehrer \& Ashkanasy, 2001; Riemer \& Klein, 2008). V-forms have minimal formal structures with hierarchical management being replaced with more social governance structures such as self-regulation and trust (Kasper-Fuehrer 
\& Ashkanasy; Pihkala, Varamaki, \& Vesalainen, 1999). V-forms are born of opportunistic desires to take advantage of a short or medium range market opportunities and collaborative projects (Kasper-Fuehrer \& Ashkanasy; Tuma, 1998). The I-form, or Innovation-form (Miles et al., 2009), is described as a new, modern form of interfirm network characterized by a focus on market exploration. Members benefit by expansion into complementary product markets. The key assets involved are knowledge and collaborative processes.

As originally defined by Provan et al., (2007) a whole network is “... g group of three or more organizations connected in ways that facilitate achievement of a common goal...often formally established and governed and goal directed ... relationships among network members are primarily nonhierarchical and participants often have substantial operating autonomy" (p. 482). Applying this definition can lead to classifying several different types of networks as whole networks. Prior literature provided examples that offered insight into whole network formation and evolution over time. Whole networks in life sciences (Powell, White, Koput, \& Owen-Smith, 2005), community economic development (Safford, 2005), and biotechnology (Owen-Smith \& Powell, 2004) shed light on the long-term objectives and challenges of an evolving field of science, an economically challenged community, and an emerging field of commercialization, respectively. These accounts of whole networks lend credence to the distinct challenges of identifying and managing whole networks. For the purposes of this paper, we explicitly distinguish a unique type of interfirm organizations to which we apply the label 'whole network'. Whole networks, as we conceive them, differ from V-forms because they are going-concern organizations, not opportunistic project based entities. In many ways, the V-form represents a potential short-term representation of a whole network. Indeed, Riemer and Klein (2008) propose that V-form organizations may evolve toward long-term network structures in order to enhance social capital and overcome some of the weaknesses inherent in virtual organizations. Unlike I-forms whose focus is innovation, whole networks seek sustainable competitive advantage where both exploitation of advantages to compete and exploration to expand and develop new growth opportunities are required. To differentiate whole networks from other network forms we believe four dimensions highlight this phenomenon most clearly: (1) source of value creation; (2) level of value appropriation; (3) location of strategic decision-making; and (4) level of entity identification.

Prior theory (Kilduff \& Tsai, 2003; Provan et al., 2007) emphasizes that whole networks have a singular, common goal. The goal of whole networks aims to serve the needs of a market segment or client base external to the network. The 
collective resources of network members are transformed through whole network capabilities to produce a marketable output. Unlike the goals of other networks that focus on development of either a new source of value that the individual firms can exploit or on a reduction in supply chain costs to benefit member firms' operational efficiencies, whole networks create value through a unified value chain.

Buyer-supplier networks emphasize transaction cost and other supply chain benefits such as supply stability or inventory management tactics (Parmigiani \& Rivera-Santos, 2011). The benefits from the transaction system are appropriated at the firm level (Dyer, 1996). R\&D networks are generally initiated to apply joint efforts to the development of a new technology, product, or standard and outcomes are commercialized by each firm independently. Conversely, in the whole network value production process, the conversion of value by an exchange with buyers occurs only at the end of the composite value chain. Whole network members do not individually exchange inputs for payment and profit via intra-network transactions; they contribute inputs toward an allocation of appropriated profit of the composite production system when the outputs are sold in the market.

Because the commercialization of outputs is a network-level concern, it follows that the critical strategic decisions in whole networks are made by a centralized body representing and holding a degree of authority for the entire group of firms. This parallels a firm in which the dominant coalition guides the strategic direction and decision making for the entity.

To summarize, whole networks are formed and managed as going concerns, competing in existing markets as a singular entity and striving to sustain their existence. This emergent form operates more akin to a single firm with members contributing to one, unified result from which all contributors draw their rewards. Further, these characteristics of whole networks are manifested in the striving for sustainable competitive advantage and the need to balance the exploitation of advantages at hand and the exploration and development of new innovations that can contribute in the future. Just as in individual firms, however, the quest for stability and the exploitation of key success factors can paradoxically lead to counter-productive tensions, inertia, and eventual loss of competitiveness. A host of issues can arise such as inefficient and isolated dyadic communications, resource coordination, and power asymmetries. A particularly salient issue involves the dilemma in managing exploitation and exploration activities.. 


\section{The Capabilities-Rigidities Dilemma}

Teece, Pisano, \& Schuen (1997) noted that while developing capabilities to gain an advantage in the current environment is necessary, it is also important to consider what will happen to those capabilities when the environment changes. Levinthal and March (1993) highlighted this challenge by explaining how core competencies of a firm tend to calcify as rigidities that institutionalize and lock in certain behavior patterns that inhibit adaptability. March (1991) explained that when knowledge is found to lead to successful outcomes, it is applied repeatedly to exploit the value it delivers. Exploitation behaviors that have become institutionalized lead to barriers to change (Hannan \& Freeman, 1984; Leonard-Barton, 1992; Lieberman $\&$ Montgomery, 1988). Core rigidities hamper innovation and adaptive behaviors thus resulting in organizational dysfunction (O'Driscoll, Carson, \& Gilmore, 2001).

As interfirm organizations develop to accentuate rapid innovation, flexibility, efficiency, and low barriers to relationship collaboration, contradictions arise that undermine and challenge those very advantages (Miles et al., 2009). For instance, the typical actions of V-form organizations toward such idealized benefits actually impede the development of the social capital and complex relationships required to sustain the level of open collaboration necessary for success (Riemer \& Klein, 2008). The consequences of organizational structures striving for these benefits often lead to fragmentation, failure, and dissolution (Riemer \& Klein, 2008; Ring \& Van de Ven, 1994). Yet the very structural characteristics that enable the achievement of these benefits can lead, if unchecked, to inabilities to react to shifts in value or competition in the market. The attention to key success factors of flexibility and speed and the exploitation of advantages gained in those areas can paradoxically result in rigidities and competency traps that lead to whole network decline and failure.

Whole networks, as we have argued, engage in competition in much the same manner as firms. Thus, the challenge of effectively balancing exploration and exploitation is clearly an issue for whole networks as well. Yet there is little if anything that is known about how whole networks can avoid the pitfalls of the capabilities-rigidities paradox and effectively balance exploitation and exploration.

\section{IMPLICATIONS OF THE CAPABILITIES-RIGIDITIES DILEMMA FOR WHOLE NETWORKS}

We expand on three important implications of the dilemma and discuss the appropriateness, or lack thereof, of firm-level theory for handling them. These implications involve challenges in: (1) allocating network assets with little or no direct 
control over those assets; (2) avoiding relational imbalances; and (3) maintaining operational stability while acknowledging the reality that member composition will evolve. In addition, we address the topic of trust as it is a critical component of effective network operations that weaves through all considerations of structure, governance, and relationship management.

\section{The Challenge of Limited Authority and Control}

In the single firm, the integration and coordination of tensions such as marketing and production, efficiency and growth, exploitation and exploration can be achieved to some degree through the formal control and authority aspects of hierarchical structures (Scott \& Davis, 2007). However, the governance and leadership mechanisms available to whole networks do not have such direct authority. The resources and capabilities of the whole network lay within the boundaries of each component firm. There is no network owner to confer legitimate authority onto agents. Member autonomy, network interdependence and the importance of trust inhibit (or prohibit) the development of hierarchical authority. Yet network-level decisions must be made to effectively allocate activities toward exploitation and exploration. If coordination processes are too weak, the effective integration of member firm activities toward the production of competitive value may be inadequately efficient or may decline over time. Capabilities may degrade into rigidities and strengths may drift toward weaknesses. Even if efforts for both exploitation and exploration are simultaneously active, without strong central leadership, the opposing tensions between the two may disrupt trust, unity, and network identification.

\section{The Challenge of Relational Imbalances}

The successful efforts to strengthen ties and build trust among whole network member organizations can lead to instability through asymmetries of power and influence. When certain dyadic relationships in a network grow tightly coupled and influential in the value-production system, proximately linked and more loosely coupled firms may begin to feel inferior, more excluded, or less powerful (Anderson, Hakansson, \& Johanson, 1994). The network may become highly influenced by the members who contribute the most valued resources and skills. Depending on the network's strategic orientation, these value imbalances may favor exploiters over explorers or vice versa. Under conditions in which certain members achieve higher status and value than others, lower esteemed firms may experience declining network identification stemming from their sense of alienation, frustration, or lack of 
network attention (Huemer, 2004). Hierarchies of power may develop and lead firms to withdraw from or seek alternatives to the existing relationships (Emerson, 1962). Granovetter (1985) remarked on this paradoxical situation by noting that conditions for opportunistic behavior are most ripe when trust is high.

\section{The Challenge of Managing Membership Composition}

Powell (1990) argued that enduring patterns of repeated trading build barriers to network entry and thus restrict access to newcomers. Building and reinforcing existing relationships often becomes the focus of networks (Levinthal \& March, 1993; Ireland, Hitt, \& Vaidyanath, 2002) and this can lead to poorer performance (Goerzen, 2007). Without being open to new exogenous parties and their potentially additive inputs and knowledge, whole networks accentuate exploitation and further build barriers to adaptation. Granovetter (1973) addressed this paradox as the strength of weak ties, explaining that strong network ties repeat the same knowledge and ties beyond the primary relationships are the ones that allow valuable new information into the network.

Accepting that change is inevitable, that existing competitive advantages will erode, and that new configurations of resources and capabilities will be required to sustain the whole network, it must be accepted that the composition of member firms is likely to require adjustment. Theory on dynamic capabilities (Teece et al., 1997) emphasizes that to maintain competitive advantage and congruence with a changing environment, organizations must be able to reconfigure their existing resources to develop new capabilities. Whole networks, too, must be cognizant that the strategic assets available from the current roster of member firms may not be adequate to compete in a changed environment. Members may need to contribute different resources and capabilities to the value chain, new assets may need to be brought into the system, and some current assets or component firms may no longer have competitive value. Due to factors such as changing strategic priorities, deficiencies in member performance, or voluntary network exit, firms will need to be removed from the network, others will voluntarily drop out, and new firms will need to be added to replace them and maintain the value chain. In summary, an element of risk in the interdependencies of the whole network is that a vital link of the production chain (i.e. an important member) may leave or not perform, thereby disrupting the network's production system until a replacement link can be activated. With each such change, the relationships and social capital built up in the network are disrupted and made, at least temporarily, less certain and stable. 


\section{Trust: A Contextual Foundation of Whole Network Operations}

In order to survive, interfirm networks must create and maintain stable relationships among member firms (Madhavan, Koka \& Prescott, 1998; Simsek, Lubatkin, \& Floyd, 2003). It is critical to recognize the importance of trust within the relations of the whole network. Theory provides us a strong foundation here, and on that foundation rests every consideration of whole network operations. But as a review of research will show, establishing high levels of trust can paradoxically lead to weaknesses and failure for the whole network.

Trust between members is critical to the success of the network because it facilitates governance and fosters the cooperative nature of the network (Inkpen, 2001; Krishnan \& Martin, 2006; Tiwana, 2008). Trust builds a 'band of tolerance' within which firms can endure periods of partial goal conflict or inequities (Madhok, 1995). Trust is a key element in whole networks due to their lack of hierarchical or equity-based authority mechanisms and because the risks of goal conflict are likely high over the life of the network. Ironically, the very work to build network identification, trust, and strong ties also lays the groundwork for network rigidity and the fragility of trust. Dyer \& Nobeoka (2000) and Granovetter (1973) showed how strong tie networks emphasizing trust and integration are at risk of developing an increasingly inward focus which can make them less able to respond to change. In sum, network success in building strong bonds of trust creates fertile ground for inertia and rigidity to grow. Trust alone may be a sufficient governance mechanism for interfirm networks that do not aspire to long-term network competitive advantage. However, prior theory and research informs that over the long term, it is unlikely that trust alone can sustain a commercial enterprise's competitive effectiveness. This is the essential challenge in whole network leadership and design: how to emphasize trust in the member relationships while also legitimizing a governance structure that protects long-term viability of the entire network.

\section{COPING WITH THE CAPABILITIES-RIGIDITIES DILEMMA}

One stream of research on how firms effectively deal with the dilemma inherent in capabilities exploitation is the stream addressing how firms can be ambidextrous. Tushman and O'Reilly (1996) described ambidexterity as the ability of a firm to simultaneously exploit and explore. This concept was refined as organizational ambidexterity by Gibson and Birkinshaw (2004). They distinguished structural mechanisms separating business units for exploitation and exploration from contextual mechanisms (e.g. overarching and compelling visions, decentralized planning, 
and cross-unit communications) that integrate the tensions into a coherent organizational strategy that fosters ambidexterity at the individual level.

Ambidexterity theory emphasizes the particular skills, knowledge, and processes that enable leaders to stand above the forces driving exploitation on one hand and exploration on the other. Ambidextrous leaders foster an integrating, 'both/ and' culture rather than an 'either/or' investment-analysis approach. Top management that is cognizant of this duality and is capable of leading in such a manner is central to contending with the capabilities dilemma (Lubatkin, Simsek, Ling, \& Veiga, 2006; Jansen, Tempelaar, Van den Bosch, \& Volberda, 2009). Further, for ambidexterity to be effective, the internal context of the firm needs an appropriate mixing of centralization with decentralization (Tushman, Smith, Wood, Westerman, \& O'Reilly, 2010), top management control with empowered initiative (Gibson \& Birkinshaw, 2004), and reliable standardization with autonomous experimentation (Tushman \& O'Reilly, 1996). Leadership must guide and control the course of the overall organization while simultaneously allowing it to function in a decentralized, segmented manner (Tushman et al., 2010). It is clear that organizational leadership and governance mechanisms play vital roles in how firms cope with the capabilities-rigidities dilemma. For whole network organizations, however, these mechanisms must address the unique challenges stemming from the capabilities-rigidities dilemma that we have previously noted. The primary challenges we have described thus far, and the intuitive and necessary counter-intuitive mechanisms for addressing them, are summarized in Figure 1. The following sections expand on the means of coping with these challenges.

\section{Figure 1}

\section{Challenges and Management Mechanisms for Whole Network Governance}

\begin{tabular}{lll}
\hline \hline Challenge & $\begin{array}{l}\text { Intuitive, logically } \\
\text { appropriate mechanisms }\end{array}$ & $\begin{array}{l}\text { Counter-intutitive mechanisms } \\
\text { for sustained performance }\end{array}$ \\
\hline Limited authority and control & Trust and reciprocity & $\begin{array}{l}\text { Authorized and legitmate rules } \\
\text { of behavior }\end{array}$ \\
Relational imbalances & $\begin{array}{l}\text { Transparency and open } \\
\text { involvement }\end{array}$ & $\begin{array}{l}\text { Legitimate leadership for managing } \\
\text { power and politics }\end{array}$ \\
$\begin{array}{l}\text { Managing membership } \\
\text { performance and composition }\end{array}$ & $\begin{array}{l}\text { Flexibility and structural } \\
\text { informality }\end{array}$ & $\begin{array}{l}\text { Standards and requirements agreed to } \\
\text { by all members }\end{array}$ \\
\hline
\end{tabular}




\section{Coping with Low Authority}

Compared to the formal authority of hierarchical structures, whole network leadership has little authority over the resources of network members. Conflicts of agendas and debates about issues such as value production, rent appropriations, and network composition necessitate a strong governance structure and formal process for clear, decisive, and necessarily endorsed leadership roles. Saz-Carranza and Ospina (2010) discuss the unique 'unity-diversity tension' (p.327) as an integral issue in whole network governance. Tensions not only exist between the forces of exploitation and exploration, but also between the unified agenda of the network as a whole and the independent strategies and agendas of each individual member firm.

To enable sustainable performance through change, organizational context and processes must simultaneously promote and manage the integration of exploitative and exploratory assets (Lubtakin, et al., 2006; Smith, Binns, \& Tushman, 2010). As benefits of exploitation accrue to network members, leadership must have adequate authority to insure that appropriate investments pursue exploration. Network leaders do not have the advantage of agency or hierarchical sources of authority like their firm-level counterparts Nevertheless, critical decisions for whole network success, often involving issues that are ambiguous, uncertain, and contentious, must be made and acted upon. Member participation and relational harmony is important, but authority mechanisms are as well. Power, as Pfeffer (1992) pointed out, is necessary to get things done in any organization. An appropriate leadership and authority structure, formal or informal, must be established, clearly communicated, and consensually agreed to at the onset of whole network operations.

Proposition 1: To cope with the capabilities-rigidities dilemma, whole networks require explicit and formalized governance processes imbued with enough authority and legitimacy to negotiate the tensions between exploitation and exploration.

\section{Coping with Risks of Relational Imbalances}

Openness and transparency are critical in governance to avoid perceptions of power grabs, coalition building, or other political moves that could harm network trust. Mechanisms that ensure decision-making transparency and provide for open flows of information among members support the development and maintenance of trust. When such systems are performed around consistent values and principles, the cycle of trust is enhanced (Colquitt \& Rodell, 2011). Transparent processes for decision authority and control must be balanced with involvement and shared pur- 
poses in order for trust and network identification to be supported. Decentralized involvement and cross-unit integration (Jensen et al., 2009; Smith \& Tushman, 2005; Tushman \& O'Reilly, 2006) supports that while maintaining centralized control, leaders of ambidextrous organizations involve their disparate component functions in planning activities to both draw knowledge from and diffuse knowledge to subunits. In the whole network context, involvement of the component firms in strategic planning likewise aids in knowledge transfer, improved coordination and decision-making, and overall network identification (Kale, Singh, \& Perlmutter, 2000).

Because members of a network-linked value chain are diverse operations and likely have different biases and backgrounds, social uncertainty exists (Riemer \& Klein, 2008). McEvily and Marcus (2005) showed that joint problem solving was the most important mechanism for building trust and increasing the strength of network relationships. Prusak and Cohen (2001) stated that social capital is best developed when members work face-to-face frequently, and Simsek et al. (2003) inform that network member interaction builds cognitive similarity.

While disproportionate input values from specific member assets likely emerge through exploitation and maximization of network value, balance of relational powers must also be maintained. Unchecked, imbalances of power and influence on decisions may skew relationships away from a harmonized, network-sustaining direction. Dhanaraj and Parke (2006) described how real or perceived power and value imbalances can lead to member isolation, migration, or attrition. Such outcomes can cause network instability. Explicitly providing systems for all members to be involved in the decisions of the whole network is a productive mechanism for both limiting the formation of power imbalances and for establishing a climate that fosters trust, understanding, and network identification. Such transparent and inclusive processes also assist in keeping tensions between members out in the open where they can be recognized and addressed.

Proposition 2: To cope with the capabilities-rigidities dilemma, whole network leadership must employ centralized guidance while promoting open, decentralized decision-making and problem solving involvement.

\section{Coping with Changes in Membership Composition}

The coordination of details such as work flows and resource commitments magnify the complexity of the whole network value chain. Each member firm is essentially a component asset. When changes in the environment occur and the nature 
of network outputs must evolve to maintain congruence, one or more member firms may no longer be relevant toward network value creation. To adapt the production system may require dropping, replacing, or adding new component firms.

Such reconfigurations in membership composition may negatively impact stability, trust, and relationship capital. To avoid system shocks, whole network members should be aware of and acknowledge that such changes to composition are inevitable. Clearly defined roles and performance standards must be set for each segment of the system and thus for each member. Procedures for removing and replacing members who are unable or unwilling to perform as needed are critical to maintain network outputs. And because continuous production is generally a requirement for competitive success, the whole network must also have mechanisms for identifying and quickly integrating new or replacement members who can pick up when prior members leave or fail to perform. In some critical operations, it may be advisable that the whole network engage in contingent relationships that may or may not come to be required. Critical elements for the ongoing survival of complex, whole network operations are managing the accumulation and aggregation of resource stocks within the whole network, ensuring that members perform as needed, and allowing for necessary reconfigurations of existing and new resources to adapt to change.

Proposition 3: To cope with the capabilities-rigidities dilemma, whole network governance systems must include provisions for managing membership composition and performance. Specifically; 3a: Whole network governance systems should include clear, explicit standards of performance for each member in order to maintain network membership.

3b: Whole network governance systems should include explicit, clear, and transparent procedures for expelling and admitting firms.

3c: Whole network governance systems should include clear, explicit, and transparent policies related to engaging alternative firms as members or sources of contingent supply for critical input components.

\section{DISCUSSION}

As organizational environments become more complex and dynamic, contradictory tensions within organizations become much more salient (Smith \& Lewis, 
2011). Many managers are likely to apply traditional 'either/or' decision approaches in leading emergent network organizations. They may abandon a principal-agent notion of leaders and followers believing that the informal, trust-based nature of the network must be matched with an equally informal and parallel style of governance. Paradox theory, however, counters that such 'either/or' thinking can be a recipe for failure (Lewis, 2000; Smith \& Lewis, 2011). Understanding how paradoxical tensions arise, how they are manifested in behaviors, and how they can be managed is an increasingly important and timely field. By examining the paradox of how capabilities of social governance (e.g. trust) can become rigidities hindering whole network adaptation and change, we have brought attention to the paradoxical nature of emergent organizations such as whole networks. While these organizations have admirable ambitions of flexibility, informality, and social bonds, in the course of pursuing long-term sustainable performance, forces of environmental change can convert such positive qualities into survival-limiting anchors.

Organizational innovations such as whole networks are increasingly competing with established firms and other networks. They create new sources of value while simultaneously reducing the value of others through this creative destruction (Schumpeter, 1950). It is therefore quite relevant for managers and scholars to begin to give attention to the how these organizations achieve and sustain competitive advantage. Our examination of paradox and governance of whole networks makes several contributions to practice and theory.

This research can assist executives who are leading, involved in, or considering joining such network organizations. Even for those firms not organizing or joining a network, such emergent competitive entities will likely influence markets directly or indirectly. Especially for small and medium sized firms constrained in their access to resources, capabilities, and markets, whole network type organizations may offer paths toward long-term success. Managers leading whole networks, or those considering founding such organizations, will benefit by understanding the paradoxical and counter-intuitive steps that likely benefit long-term network performance. By understanding how network governance structures play a role in the long-term viability of a network, managers considering joining such a network can benefit in an enhanced ability to assess such opportunities. A trust-based, socially integrated, and "no rules; no structure; no contracts" type of alliance network may work for certain goals or for certain period of time, but environmental forces and the "dark side of close relationships" (Anderson \& Jap, 2005; p. 75) can transform these informal governance mechanisms into inertial barriers that prohibit market-required change. Managers will do well to recognize that the way they operate their own 
firms, however successful, is unlikely to work as a leadership and management style for the unique nature of a whole network structure. For leaders of member firms, too, an understanding of the realities of environmental change and its consequences for whole network governance can be beneficial in decisions about network relationships, including decisions to join or remain in a network. Alternatives to a traditional principal-agent control system are available (Granovetter, 2005). Leveraging social capital to enable formal governance rules and standards is quite achievable. With an awareness of the paradoxical challenges we have noted, leaders who can apply their innovativeness toward governance practices that not only manage inherent tensions, but also leverage social assets toward creating strong governance are likely to create enduring organizational performance.

For scholars, understanding that whole networks are subject to firm-type challenges such as the capabilities-rigidities dilemma highlights that other firm-based theory may also have relevant extensions to emergent network organizations. Our research additionally sheds light on a boundary condition for social mechanisms. That is, how and when they may not operate as effective governance tools for all networks. Reliance on trust and reciprocity has its place in network theory; however, it must be recognized that these positive factors can also fracture or become inhibitors to change (Anderson et al., 1994; Granovetter, 1973; 1985). We do not dispute or attack the role of such mechanisms in network governance (Jones et al., 1997). We agree that building trust and social cohesion should remain an objective in all networks. However, dependence on social mechanisms to sustain the organization through the forces of time and change is risky. The emergent network forms we have addressed in this paper operate with a unique combination of motive and structure. That is, they are informally and non-hierarchically networked firms that have come together to produce a singular value-chain and compete as a singular entity as a going concern. To achieve this, considerations of firm-level theory on competition and sustainable competitive advantage (e.g. Barney, 1991; Leonard-Barton, 1992; Teece et al., 1997; Tushman \& O'Reilly, 1996) become relevant. Thus, more firm-like governance, we argue, becomes necessary and relevant as well.

While the present study better informs the literature on network-level competitive theory, there are significant challenges going forward to validate and extend our conclusions. In particular, one challenge will be gaining access to whole networks to test the propositions put forth in this manuscript. Since the subject involves a loosely formalized emerging form of an interorganizational relationship, it could prove difficult for researchers to identify, observe, and assess the early formations and ongoing management of a whole network. To address this challenge, a 
mixed-method approach could be used to historically examine the formation aspects of the whole network, utilizing event history analysis. A longitudinal case study approach to study the ongoing management of the whole network could then be used to examine leadership and management. In such a new area, where existing theory may not hold and where the relative importance of elements and relationships are not clearly understood, a case study approach is a very appropriate methodology (Eisenhardt, 1989). Once researchers have better organized and refined the vital components, more targeted empirical research can follow. This path can extend this stream toward statistical validation, predictions of contingent conditions, and identification of configurations of governance mechanisms that will further help managers make appropriate choices to lead network-structured competitive entities.

Emergent organizational forms are, by definition, still evolving and thus subject to continued radical change. Any conclusions and implications at this juncture must be viewed in that light. However, we are confident that based on prior theory and empirical research, network governance is, and will continue to be, a critical answer for how whole network organizations manage the implications of inherent challenges such as the capabilities-rigidities dilemma.

\section{$\overline{\text { REFERENCES }}$}

Anderson, E., \& Jap, S. D. (2005). The dark side of close relationships. MIT Sloan Management Review, 46(3), 75-82.

Anderson, J.C., Hakansson, H., \& Johanson, J. (1994). Dyadic business relationships within a business network context. Journal of Marketing, 58(4), 1-15.

Barney, J. (1991). Firm resources and sustained competitive advantage. Journal of Management, 17(1), 99-120.

Colquitt, J.A., \& Rodell, J.B. (2011). Justice, trust, and trustworthiness: A longitudinal anlaysis integrating three theoretical perspectives. Academy of Management Journal, 54(6), 1183-1206.

Contractor, F.J., \& Lorange, P. (2002). The growth of alliances in the knowledge-based economy. International Business Review, 11, 485-502.

Dhanaraj, C., \& Parke, A. (2006). Orchestrating innovation networks. Academy of Management Review, 31(3), 659-669.

Dyer, J.H. (1996). Specialized supplier networks as a source of competitive advantage: Evidence from the automotive industry. Strategic Management Journal, 17, 271-291. 
Dyer, J.H., \& Nobeoka, K. (2000). Creating and managing a high-performance knowledge-sharing network: The Toyota case. Strategic Management Journal, $21,345-367$.

Eisenhardt, K. M. (1989). Building theories from case study research. Academy of Management Review, 14(4), 532-550.

Emerson, R. (1962). Power-dependence relations. American Sociological Review, 27, 31-40.

Gibson, C. B., \& Birkinshaw, J. (2004). The antecedents, consequences, and mediating role of organizational ambidexterity. Academy of Management Journal, 47(2), 209-226.

Gimeno, J. (2004). Competition within and between networks: The contingent effect of competitive embeddedness on alliance formation. Academy of Management Journal, 47(6), 820-842.

Goerzen, A. (2007). Alliance networks and firm performance: The impact of repeated partnerships. Strategic Management Journal, 28, 487-509.

Granovetter, M.S. (1973). The strength of weak ties. American Journal of Sociology, $78(6), 1360-1380$.

Granovetter, M.S. (1985). Economic action and social structure: The problem of embeddedness. American Journal of Sociology, 91(3), 481-510.

Granovetter, M. (2005). The impact of social structure on economic outcomes. Journal of Economic Perspectives, 19(1), 33-50.

Guidice, R.M., Vasudevan, A., \& Duysters, G. (2003). From 'me against you' to 'us against them': Alliance formation based on inter-alliance rivalry. Scandinavian Journal of Management, 19, 135-152.

Hannan, M.T., \& Freeman, J. (1984). Structural inertia and organizational change. American Sociological Review, 49(2), 149-164.

Huemer, L. (2004). Balancing between stability and variety: Identity and trust tradeoffs in networks. Industrial Marketing Management, 33, 251-259.

Inkpen, A. C. (2001). Strategic alliances. In Hitt, M. A., Freeman, E., \& Harrison, J. S. (Eds.), Handbook of Strategic Management (pp. 409-432). Oxford, UK: Blackwell Publishers.

Ireland, R.D., Hitt, M.A., \& Vaidyanath, D. (2002). Alliance management as a source of competitive advantage. Journal of Management, 28(3), 413-446.

Jansen, J. J. P., Tempelaar, M. P., van de Bosch. B., \& Volberda, H. W. (2009). Structural differentiation and ambidexterity: The mediating role of integration mechanisms. Organization Science, 20(4), 797-811. 
Jarillo, J.C. (1993). Strategic Networks: Creating the Borderless Organization. Oxford: Butterworth-Heinemann.

Jones, C., Hesterly, W.S., \& Borgotti, S.P. (1997). A general theory of network governance: Exchange conditions and social mechanisms. Academy of Management Review, 22(4), 911-945.

Kale, P., H. Singh, \& Perlmutter, H. (2000). Learning and protection of proprietary assets in strategic alliances: Building relational capital. Strategic Management Journal, 21, $217-223$.

Kasper-Fuehrer, E.C., \& Ashkanasy, N.M. (2001). Communicating trustworthiness and building trust in interorganizational virtual organizations. Journal of Management, 27, 235-254.

Kilduff, M., \& Tsai, W. (2003). Social Networks and Organizations. London. SAGE Krishnan, R and Martin, X. (2006). When does trust matter to alliance performance? Academy of Management Journal, 49(5), 894-917.

Leonard-Barton, D. (1992). Core capabilities and core rigidities: A paradox in managing new product development. Strategic Management Journal, 13, 111-125.

Lewis, M.W. (2000). Exploring paradox: Toward a more comprehensive guide. Academy of Management Review, 25(4), 760-776.

Levinthal, D. A., \& March, J.G. (1993). The myopia of learning. Strategic Management Journal, 14, 95-112.

Lieberman, M. B., \& Montgomery, D. B. (1988). First mover (dis)advantages: Retrospective and link with the resource-based view. Strategic Management Journal, 19(12), 1111-1125.

Lubatkin, M. H., Simsek, Z., Ling, Y., \& and Veiga, J. F. (2006). Ambidexterity and performance in small-to-medium-sized firms: The pivotal role of top management team behavioral integration. Journal of Management, 32(5), 646-672.

Madhavan, R., Koka, B.R., \& Prescott, J.E. (1998). Networks in transition: How industry events (re)shape interfirm relationships. Strategic Management Journal, 19, 439-459.

Madhok, A. (1995). Opportunism and trust in joint venture relationships: An exploratory study and a model. Scandinavian Journal of Management, 11(1), 57-74.

March, J.G. (1991). Exploration and exploitation in organizational learning. Organization Science, 2(1), 71-87.

McEvily, B., \& Marcus, A. (2005). Embedded ties and the acquisition of competitive capabilities. Strategic Management Journal, 26, 1033-1055. 
Meiseberg, B., \& Ehrmann, T. (2012). Tendency to network of small and medium-sized enterprises: Combining organizational economics and resource-based perspectives. Managerial and Decision Economics. Retrieved from Wiley Online Library. doi: 10.1002/mde. 2590

Miles, R.E., \& Snow, C.C. (1992). Causes of failure in network organizations. California Management Review, Summer, 53-72.

Miles, R.E., Miles, G., Snow, C.C., Blomqvist, K., \& Rocha, H. (2009). The I-form organization. California Management Review, 51(4), 61-76.

O’Driscoll, A., Carson, D., \& Gilmore, A. (2001). The competence trap: Exploring issues in winning and sustaining core competence. Irish Journal of Management, 22(1), 73-90.

O'Reilly, III, C.A., \& Tushman, M.L. (2008). Ambidexterity as a dynamic capability: resolving the innovator's dilemma. Research in Organizational Behavior, 28, 185-206.

Parkhe, A., Wasserman, S., \& Ralston, D.A. (2006). New frontiers in network theory development. Academy of Management Review, 31(3), 560-568.

Owen-Smith, J., \& Powell, W.W. (2004). Knowledge networks as channels and conduits: The effects of spillovers in the Boston biotechnology community. Organization Science, 15(1): 5-21.

Parmigiani, A, \& Rivera-Santos, M. (2011). Clearing a path through the forest: A meta-review of Interorganizational relationships. Journal of Management, 37(4), 1108-1136.

Pedersen, C., \& Nagengast, J. (2008). The virtues of the virtual organization. Strategic HR Review, 7(3), 19-25.

Pfeffer, J. (1992). Understanding power in organizations. California Management Review, 34(2), 29-50.

Phan, P.H., Siegel, D.S., \& Wright, M. (2005). Science parks and incubators: Observations, synthesis, and future research. Journal of Business Venturing, 20, 165-182.

Pihkala, T., Varamaki, E., \& Vesalainen, J. (1999). Virtual organization and the SMEs: A review and model development. Entrepreneurship \& Regional Development, 11(4), 335-349.

Powell, W.W. (1990). Neither market nor hierarchy: Network forms of organization. Research in Organizational Behavior, 12, 295-336.

Powell, W.W., White, D.R., Koput, K.W., \& Owen-Smith, J. (2005). Network dynamics and field evolution: The growth of interorganizational collaboration in the life sciences. American Journal of Sociology, 110(4): 1132-1205. 
Provan, K.G., Fish, A., \& Sydow, J. (2007). Interorganizational networks at the network level: A review of the empirical literature on whole networks. Journal of Management, 33(3), 479-516.

Prusak, L., \& Cohen, D. (2001). How to Invest in Social Capital. Harvard Business Review, 79(6), 86-93

Raab, J., \& Kenis, P. (2009). Heading toward a society of networks: Empirical developments and theoretical challenges. Journal of Management Inquiry, 18(3), 198-210.

Raisch, S., \& Birkinshaw, J. (2008). Organizational ambidexterity: Antecedents, outcomes, and moderators. Journal of Management, 34(3), 375-409.

Riemer, K., \& Klein, S. (2008). Is the V-form the next generation organization? An analyisis of challenges, pitfalls and remedies of ICT-enabled virtual organisations based on social capital theory. Journal of Information Technology, 23, 147-162.

Ring, P.S., \& Van de Ven, A.H. (1994). Developmental processes of cooperative interorganizational relationships. Academy of Management Review, 19(1), 90-118.

Safford, S. 2004. Why the garden club couldn't save Youngstown: Civic infrastructure and mobilization in economic crises. Working paper, MIT Industrial Performance Center, Cambridge, MA.

Saz-Carranza, A., \& Ospina, S.A. (2010). The behavioral dimension of governing interorganizational goal-directed networks-managing the unity-diversity tension. Journal of Public Administration Research and Theory, 21, 327-365.

Schumpeter, J.A. (1950). Capitalism, Socialism, and Democracy, $3^{\text {rd }}$ edition. New York: Harper and Brothers.

Scott, W.R., \& Davis, G.F. (2007). Organizations and Organizing: Rational, Natural, and Open Systems. Upper Saddle River, New Jersey: Pearson Education

Simsek, Z., Lubatkin, M.H., \& Floyd, S.W. (2003). Inter-firm networks and entrepreneurial behavior: A structural embeddedness perspective. Journal of Management, 29(3), 427-442.

Smith, W. K., Binns, A., \& Tushman, M. L. (2010). Complex business models: Managing strategic paradoxes simultaneously. Long Range Planning, 43(2-3), 448461.

Smith, W.K. \& Lewis, M.W. (2011). Toward a theory of paradox: A dynamic equilibrium model for organizing. Academy of Management Review, 36(2), 381-403.

Smith, W. K., \& Tushman, M. L. (2005). Managing strategic contradictions: A top management model for managing innovation streams. Organization Science, 16(5), 522-536. 
Snow, C.C., Miles, R.E., \& Coleman, H.J. (1992). Managing 21st century network organizations. Organizational Dynamics, 20, 5-20.

Sydow, J. \& Windeler, A. (1998). Organizing and evaluating interfirm networks: A structurationist perspective on network processes and effectiveness. Organization Science, 9(3), 265-284.

Teece, D.J., Pisano, G, \& Schuen, A. (1997). Dynamic capabilities and strategic management. Strategic Management Journal, 18(7), 509-534.

Tiwana, A. (2008). Do bridging ties complement strong ties? An empirical examination of alliance ambidexterity. Strategic Management Journal, 29(3), 251-272.

Tuma, A. (1998). Configuration and coordination of virtual production networks. International Journal of Production Economics, 56/57, 641-648.

Tushman, M. L., \& O’Reilly III, C. A. (1996). Ambidextrous organizations: Managing evolutionary and revolutionary change. California Management Review, 38(4), 8-30.

Tushman, M., Smith, W. K., Wood, R. C., Westerman, G., \& O'Reilly, C. (2010). Organizational designs and innovations streams. Industrial and Corporate Change, 19(5), 1331-1366.

\section{BIOGRAPHICAL SKETCH OF AUTHORS}

William R. Carter is a doctoral candidate in strategic management at the University of North Texas. After receiving his MBA from the Cox School of Business at Southern Methodist University, he spent over twenty-five years in industry as a marketing and strategic planning executive. His research interests are paradoxes in strategic leadership, top management team functioning in small and medium-sized enterprises, and sustainability entrepreneurship.

Phillip E. Davis is a doctoral candidate at the University of North Texas where his studies focus on strategic management and entrepreneurship. He received his MBA and BS in industrial engineering from Clemson University. His research interests include capability development, strategy process, and strategic entrepreneurship. Prior to his doctoral studies, Phillip held managerial and executive positions in manufacturing and banking.

Julia L. Herchen is a doctoral candidate in organizational behavior at the University of North Texas. She received her MBA from Baylor University and her BBA from Eastern New Mexico University. Prior to pursuing a PhD, Julia was a financial executive, primarily in the commercial mortgage sector. Julia's research 
interests include behavioral ethics, pro-social behavior, deviant workplace behavior, leadership, organizational misconduct and corporate social responsibility.

Vallari Chandna is a doctoral candidate in the Department of Management at the University of North Texas. She earned her MBA from the same university in organizational behavior and a degree in law (BA.LL.B) from India. Her current research interests in organizational theory and entrepreneurship including new organizational forms (temporary organizations), individual and organizational issues in start-ups, de-growth, inter-organizational relationships and identity issues. 